\title{
A morte na perspectiva de enfermeiros e médicos de uma Unidade de Terapia Intensiva pediátrica
}

\author{
Death in point of view of nurses and \\ physicians in a pediatric \\ Intensive Care Unit
}

\author{
Evandro de Quadros CHERER ${ }^{1}$ \\ Alberto Manuel QUINTANA ${ }^{2}$ \\ Ursula Maria Stockmann PINHEIRO ${ }^{3}$
}

\begin{abstract}
Resumo
O presente estudo visou investigar a significação feita, em relação à morte, por enfermeiros e médicos de uma Unidade de Terapia Intensiva pediátrica. Participaram oito profissionais que atuavam, no mínimo há seis meses, em uma Unidade de Terapia Intensiva pediátrica do interior do Rio Grande do Sul, a saber, quatro enfermeiros e quatro médicos. Foi realizada entrevista semiestruturada guiada por eixos norteadores. Os dados foram analisados por meio da análise de conteúdo, da qual surgiram duas categorias: "A morte como fracasso" e "A morte escamoteada". Os resultados apontam que, para os participantes, a morte foi tipicamente significada como fracasso. Além disso, esta também foi ocultada, negada e banalizada, através de diversos recursos empregados na tentativa de escamoteá-la. Compreende-se que a elaboração psíquica apresenta-se como a melhor estratégia diante de um contexto tão complexo, sendo sugeridas abordagens educativas e terapêuticas que proporcionem espaços elaborativos para esses profissionais.
\end{abstract}

Palavras-chave: Morte; Pediatria; Psicologia; Unidade de Terapia Intensiva.

\begin{abstract}
The aim of the present study was to investigate the significance of death from the perspective of nurses and physicians in a pediatric Intensive Care Unit. Four nurses and four physicians, who had been working in the pediatric Intensive Care Unit of a hospital in Rio Grande do Sul for at least six months, participated in this study. A semi-structured interview with a pre-determined set of open questions was conducted. Data were analyzed using content analysis leading to the following two categories: "Death as failure" and "Death concealed". The results show that death was

$\checkmark \nabla v$

1 Universidade Federal do Rio Grande do Sul, Instituto de Psicologia, Programa de Pós-Graduação em Psicologia. Porto Alegre, RS, Brasil.

2 Universidade Federal de Santa Maria, Departamento de Psicologia, Programa de Pós-Graduação em Psicologia e Enfermagem. R. Marechal Floriano Peixoto, 1750, $3^{\circ}$ Andar, Sala 315, Centro, 97015-372, Santa Maria, RS, Brasil. Correspondência para/Correspondence to: A.M. QUINTANA. E-mail: <albertom.quintana@gmail.com>.

3 Enfermeira. Gramado, RS, Brasil.
\end{abstract}


typically seen as failure. Moreover, death was also usually hidden, denied, or even trivialized. The participants used several resources in trying to conceal it. However, it is understood that the psychic development itself is best strategy to deal with such a complex context. Therefore, educational and therapeutic approaches that help professionals to achieve psychic development should be adopted.

Keywords: Death; Pediatrics; Psychology; Intensive Care Unit.

A partir da psicanálise compreende-se o luto como as repercussões advindas da perda de uma pessoa amada ou de abstrações depositadas em seu lugar. Nesse cenário, a libido, outrora investida no objeto perdido, é retirada, pois o teste da realidade evidencia que esse objeto não existe mais. Porém, o ser humano não abandona facilmente uma posição libidinal uma vez ocupada. Sendo assim, as exigências da realidade são atendidas lentamente e, paralelamente a isso, a existência psíquica do objeto continua a ser mantida (Freud, 1917/2004).

Nesse sentido, entende-se que o ser humano, desde a mais tenra idade, vivencia experiências de luto por meio da perda do útero, da amamentação, dos dentes, dos brinquedos, além de outras perdas intrínsecas ao processo de amadurecimento. Essas situações permitem que cada pessoa se depare com o sofrimento e a frustração ocasionadas pelas limitações inerentes ao viver (Borges, Genaro, \& Monteiro, 2010). As perdas e, em última análise, a incompletude, são impostas pela realidade, assim como a própria finitude. Entretanto, algumas vicissitudes da existência, incluindo-se entre essas a morte, tendem a ser recusadas numa insistente busca por um estado de onipotência original alucinatoriamente experimentado quando se era bebê (Osório, 2003). Desse modo, o aparelho psíquico humano, por meio de suas atividades, construções criativas ou sintomáticas, pode negar, reconhecer e simultaneamente elaborar as separações, o desconhecido e até mesmo a morte (Dias, 2003).

No século $X X$, os fenômenos concernentes ao ciclo vital humano, como nascimento, desenvolvimento e morte, adquiriram um caráter tecnicista (Ariès, 2003). Esta última passou a ser ocultada e a simbolizar o fracasso, sentimento desenvolvido, sobretudo, pela cultura ocidental, na qual uma vida com qualidade passou a ser associada a uma vida longa e produtiva (Silva, 2003). Nesse escopo, os acontecimentos que ocorriam espontaneamente no domicílio passaram a acontecer no hospital e a serem demarcados pela equipe de saúde quanto à sua hora (Ariès, 2003).

Nesse contexto, contemporaneamente, a Unidade de Terapia Intensiva (UTI) possui atendimento integral e especializado para pacientes graves e recuperáveis (Sanches \& Carvalho, 2009). Particularmente, a UTI pediátrica destina-se ao atendimento de pacientes de 29 dias até 15 anos incompletos, sendo que os profissionais possuem um papel essencial no cuidado e tratamento das crianças internadas na unidade, assim como de seus familiares (Beckstrand, Rawle, Callister, \& Mandleco, 2010). Ademais, a UTI pediátrica é um ambiente de trabalho que, além de permeado por aspectos referentes à morte, possui a especificidade de os pacientes internados serem muito jovens. Quanto a isso, a literatura indica que a morte de uma criança pode ser vista como um processo assustador pelos profissionais (Azambuja, Pires, Vaz, \& Marziale, 2010; Mattos et al., 2009). Nesse sentido, o presente estudo visou investigar a significação feita, em relação à morte, por enfermeiros e médicos de uma UTI pediátrica.

Desse modo, no tocante as equipes de saúde que atuam em hospitais, pode-se compreender que elas exercem suas profissões no local instituído socialmente para que a morte ocorra e, desta forma, esta passa a ser parte de seu cotidiano. Quanto a isso, pode-se considerar as contribuições de Dejours (1992; 1994), as quais afirmam que o trabalho possui particularidades que, em sua maioria, são determinadas independentemente da vontade do sujeito. O trabalhador, ainda que possua uma subjetividade preexistente, se depara com a realidade do trabalho. Desse modo, há a possibilidade do profissional sofrer transformações, assim como a realidade do trabalho ser alterada por meio da suplementação da subjetividade (Dejours, 1992; 1994). Com efeito, o profissional do contexto hospitalar passou a vivenciar a morte em seu cotidiano, tipicamente escamoteando 
suas repercussões e o luto vivenciado, o que foi percebido como indicador de fraqueza ou de inadequação para o exercício das funções profissionais (Pessini \& Bertachini, 2004).

Além desses fatores, esse mesmo profissional possui o conhecimento de que podem existir pacientes mais significativos para ele, sendo que, em alguns casos, há o desenvolvimento de relações para além da esfera profissional. Com isso, o falecimento desse tipo de paciente pode enlutar o trabalhador, assim como promover todas as reações próprias a esse contexto (Gerow et al., 2010). A respeito disso, Ribeiro, Baraldi e Silva (1998) afirmaram que o nível de envolvimento que o profissional desenvolve com o paciente durante a hospitalização está relacionado à intensidade de afeto vivida durante o falecimento deste último. Consequentemente, nesse momento, sentimentos de baixa autoestima, autorreprovação e desamparo podem ocorrer (Silva et al., 2010a). Assim, diante de circunstâncias emocionalmente desgastantes, os profissionais da saúde experimentam diversos sofrimentos, os quais, comumente, são escondidos. Esse ocultamento se dá pela utilização de recursos defensivos, entre esses a negação, o distanciamento, a sustentação de relações superficiais com os pacientes, bem como a instituição de rotinas e protocolos (Davies et al., 1996).

Nesse cenário, a partir das conceituações de Dejours (1992), compreende-se que os profissionais tendem a formar ideologias defensivas diante do medo advindo da realidade do trabalho. Essas defesas possuem como finalidade disfarçar, reprimir e esconder uma ansiedade perigosa, tratando-se de um mecanismo elaborado especificamente pelo grupo de trabalho, não estando circunscrito a cada sujeito. Considerando-se esses aspectos, o presente artigo visou investigar a significação feita, em relação à morte, por enfermeiros e médicos de uma UTI pediátrica, trazendo um recorte de duas categorias obtidas a partir da análise dos dados do estudo.

\section{Método}

\section{Participantes}

Participaram deste estudo oito profissionais que atuavam em uma UTI pediátrica, a saber, quatro enfermeiros e quatro médicos. Todos eram do sexo feminino, exceto um médico. Como critério de inclusão no estudo foi definido que os participantes deveriam ser enfermeiros ou médicos com tempo de atuação profissional de, no mínimo, seis meses na UTI pediátrica. Esses critérios acerca do tempo foram empregados, pois acredita-se que a complexidade do tema investigado demanda a seleção de participantes que estejam de fato inseridos no contexto pesquisado, a fim de se corresponder aos objetivos da pesquisa. Com isso, os participantes, ainda que de duas profissões distintas, foram estudados como uma única amostra.

A definição do número de participantes ocorreu por meio do critério de amostragem de saturação teórica. O fechamento amostral nesse critério é operacionalmente definido como a suspensão de inclusão de novos participantes quando os dados obtidos passam a apresentar, na avaliação do pesquisador, certa redundância ou repetição, não sendo considerado relevante continuar a coleta de dados (Denzin \& Lincoln, 1994).

\section{Instrumentos e procedimentos}

Foi realizada uma pesquisa qualitativa, pois procurou-se investigar o fenômeno sem reduzi-lo a operacionalizações de variáveis (Minayo, 2010). Além disso, trata-se de um estudo exploratório, já que pretendeu-se estudar o que acontece com o fenômeno em questão em um determinado contexto por meio da procura de novos insights e da elaboração de questões (Robson, 1993).

Como instrumento de coleta de dados foi utilizada uma entrevista semiestruturada, tendo como questão norteadora: "Como é, para você, a morte em seu cotidiano na UTI pediátrica?". A entrevista foi conduzida através dos seguintes eixos norteadores: a morte do primeiro paciente e no cotidiano; comunicação sobre a morte com os familiares do paciente; situações relacionadas ao tema que mais marcaram o profissional durante o trabalho na UTI pediátrica; a morte na UTI pediátrica e UTI; a comunicação com os colegas a respeito do tema; a inserção na UTI pediátrica e a vida pessoal; a morte na história pessoal do profissional. 
Como local de seleção dos participantes foi escolhida a UTI pediátrica de um hospital universitário no interior do Rio Grande do Sul. Essa unidade atende pacientes com idade a partir dos 29 dias até os 14 anos, 11 meses e 29 dias. Ela possui capacidade de cinco leitos, contando com uma equipe multidisciplinar. Esta é composta por sete enfermeiros, onze técnicos de enfermagem, sete auxiliares de enfermagem, onze médicos, quatorze médicos residentes (oito do $1^{\circ}$ ano, cinco do $2^{\circ}$ e um do $3^{\circ}$ ), além de um psicólogo e três fisioterapeutas.

Os profissionais que atenderam aos critérios de inclusão do estudo foram convidados a participar. Naquele momento, eles foram informados acerca dos objetivos da pesquisa, assim como dos procedimentos que seriam realizados. Uma vez aceita a participação, foi solicitada a leitura e assinatura do Termo de Consentimento Livre e Esclarecido. Posteriormente, iniciou-se a coleta de dados por meio da aplicação de entrevista semiestruturada guiada por eixos norteadores, realizada em uma sala cedida pelo próprio hospital. Estas foram gravadas em meio digital e posteriormente transcritas na íntegra. O sigilo dos participantes foi preservado por meio da adoção de códigos para identificação das falas, tais como as siglas ENF e MED para enfermeiros e médicos, respectivamente, seguidos de números (por exemplo: ENF1, ENF2, MED1, MED2, e assim sucessivamente). Este estudo foi aprovado pelo Comitê de Ética da instituição em que foi realizado (Protocolo n 0157.0.243.000-11) no dia 19 de agosto de 2011, atendendo aos procedimentos éticos exigidos pela Resolução nº 196/96, do Conselho Nacional de Saúde (Brasil, 1996), bem como pela Resolução n 016/2000, do Conselho Federal de Psicologia (Brasil, 2000).

\section{Resultados e Discussão}

Análise de conteúdo qualitativa (Bardin, 2008) foi utilizada a fim de se investigar a significação feita, em relação à morte, por enfermeiros e médicos de uma UTI pediátrica. Mais especificamente, foi realizada a leitura flutuante do material transcrito para a impregnação de seu conteúdo, sendo que as entrevistas foram, posteriormente, categorizadas em tópicos emergentes conforme critérios de relevância e repetição (Turato, 2003). Com isso, formaram-se duas categorias temáticas: "A morte como fracasso" e "A morte escamoteada". Cada uma delas será exemplificada com excertos extraídos das falas dos participantes, sendo também discutidas com base na literatura.

\section{A morte como fracasso}

Dentro desta categoria foram incluídos os relatos dos enfermeiros e médicos que versaram sobre a morte e seu significado como fracasso. A respeito disso, os participantes relataram que há momentos nos quais, por mais que se aguarde o êxito do tratamento, este tem sua finalização com o falecimento do paciente. Diante disso, alguns profissionais disseram sentirem-se incapazes e impotentes: "Nem sempre a gente consegue, como eu te disse, nem sempre se tem sucesso naquilo que se faz, embora se espere" (MED4); "Eu sinto impotência, apesar de não ter sido eu aquela causadora assim" (MED3). Isso corrobora com o estudo de Gerow et al. (2010) na compreensão de que os profissionais que atuam no âmbito hospitalar podem vivenciar sentimentos de impotência com a morte de pacientes, sendo isto fonte de estresse e sofrimento (Vieira, Souza, \& Sena, 2006). Esses sentimentos de não aceitação, insatisfação e de impotência podem estar vinculados ao sentimento de culpa (Mattos et al., 2009; Silva et al., 2010a) e surgirem em decorrência da própria formação profissional direcionada para a recuperação da vida (Aguiar, Veloso, Pinheiro, \& Ximenes, 2006).

Nessa perspectiva, os participantes, muitas vezes, se implicaram na morte do paciente, ou seja, o falecimento foi vinculado ao insucesso profissional, ao não conseguir o que realmente se esperava, ou seja, a vida. Desse modo, se o sucesso vem entrelaçado à vida, a morte passa a significar fracasso. Corroborando com esse pensamento, o estudo de Aguiar et al. (2006) afirmou que a compreensão dos profissionais a respeito do fracasso concerne a um sentimento de onipotência, que apesar de ser ocultado, se expressa corriqueiramente por meio do sentimento de impotência. Com efeito, a relativa 
falta de controle sobre o tratamento do paciente e a iminência da morte conduzem os profissionais a enfrentar suas limitações. Diante disso, surge a sensação de teste, como se a conservação da vida dependesse apenas da competência da equipe (Aguiar et al., 2006).

Por sua vez, no estudo de Shorter e Stayt (2010), a morte como fracasso relacionou-se ao sofrimento, sendo este usualmente vivenciado de acordo com a intensidade de vinculação do médico/enfermeiro com o paciente quando este vem a óbito, isto é, o envolvimento emocional tende a ser proporcional ao pesar vivenciado pelo profissional (Vieira et al., 2006). Os resultados do presente estudo foram ao encontro desses achados. Assim, o tempo de convivência, entendido como agente facilitador de vínculo, bem como a intensidade do envolvimento, foram fatores determinantes para o modo como a equipe vivenciou a morte e o luto do paciente: "Eu acho que tem pessoas que se ligaram muito e sofreram com aquela morte como se fosse um familiar" (MED3); "Às vezes tu te envolve muito com uma criança e isso quando vai a óbito é bem difícil. E não só pra mim, eu vejo isso em toda a equipe" (ENF4).

A morte como fracasso, assim como os intensos sentimentos de pesar relacionados a ela, surgiram diante de um envolvimento emocional considerado forte e longo com a criança. Além do mais, alguns profissionais relataram passar a perceber o paciente como se fosse um ente familiar. Com isso, corrobora-se com o estudo de Aguiar et al. (2006), onde entende-se que, perante a morte de um paciente com o qual se estabeleceu um intenso envolvimento, pode ocorrer uma resposta de descontrole e desorientação, uma vez que esse vínculo é rompido, promovendo um difícil processo de luto.

A relação profissional-paciente também se apresentou marcada pela empatia, sendo esta compreendida como a possibilidade de sentir o que se sentiria caso estivesse em situação ou circunstância experimentada por outra pessoa (Osório, 2003). Esse mecanismo, exemplificado pelos excertos a seguir, foi relatado pelos enfermeiros e médicos como sendo presente e essencial para o trabalho com o processo de adoecer e morrer na UTI Pediátrica: "É difícil tu tratar se não houver uma empatia" (MED3); "Se colocar no lugar do outro é a melhor maneira, acho que isso é a dita compaixão que tu tens de te colocar no lugar do outro" (MED2). Por sua vez, Silva, Valença e Germano (2010b) definem o sentimento da compaixão como despojar-se de si mesmo para colocar-se no lugar do outro. Dessa maneira, por meio do respeito que sentem pelo paciente e sua família, os profissionais entrevistados expressaram compaixão em suas falas, inclusive pela sensibilidade com o sofrimento da família das crianças internadas e falecidas.

\section{A morte escamoteada}

Dentro desta categoria foram incluídos os relatos dos enfermeiros e médicos que versaram sobre a morte escamoteada, isto é, aquela que por mais que aconteça é negada, ocultada e dissimulada. A significação da morte envolvendo a escamoteação apresentou-se perceptível quando as falas dos participantes estavam relacionadas, sobretudo, ao âmbito profissional. Nesse sentido, os profissionais participantes falaram acerca dessas transformações, dizendo existir influência na vida pessoal por trabalharem no contexto da UTI pediátrica e vice-versa. Contudo, essa dupla influência muitas vezes foi negada ou ocultada. Com isso, percebeu-se um contínuo esforço desempenhado pelos participantes em encobrir as diversas implicações do trabalho, como pode ser exemplificado nos trechos a seguir: "Eu consigo dividir [o trabalho da vida pessoal], consigo esconder, como eu te digo, deixar isso quietinho" (ENF2); "Eu me sinto triste, porém claro que sim, isso não atrapalha no meu cotidiano... após um plantão difícil... isso claro que reflete no dia, mas no final das contas, na vida assim, a gente não acaba digerindo essas coisas" (MED3).

A ambivalência subjacente às falas acima remete a algo recorrente na fala dos participantes, os quais expressaram que ainda que ocorra a tentativa de impedir que o trabalho na UTI pediátrica os afete, este, de alguma maneira, interfere em suas vidas. De modo semelhante, suas experiências pessoais alteraram o modo como vivenciam o cotidiano 
da UTI pediátrica. Esse fato corrobora com os estudos de Dejours (1992; 1994), os quais afirmam a dupla interferência entre o trabalho e a vida pessoal do trabalhador. Além disso, percebeu-se a fragilidade desses profissionais ao lidarem com as transformações advindas do trabalho na UTI pediátrica, uma vez que a recusa das mesmas apresentou-se como um dos recursos mais empregados. Entretanto, entende-se que essas alterações são intrínsecas, sendo imprescindíveis para a adequada execução do trabalho e manutenção da saúde dos trabalhadores, que esses ocorridos não sejam negados, mas compreendidos e, assim, melhor trabalhados.

No que diz respeito ao envolvimento emocional, este pode ser compreendido como a habilidade de transcender a si mesmo e interessar-se pelo outro. Essa relação é frequentemente facilitada pela qualidade e quantidade de tempo de interação entre profissional e paciente. Ainda que alguns médicos/enfermeiros tenham evitado o envolvimento emocional, distanciando-se dos pacientes e de seus familiares, acabaram por se envolver em alguma medida, uma vez que esse tipo de relação é intrínseco ao cuidado (Palú, Labronici, \& Albini, 2004). Com isso, constatou-se nas falas dos participantes uma aparente demarcação entre envolvimento emocional e a relação profissional. Essa fronteira foi comumente manifesta como necessária para a realização do trabalho e essencial para a saúde do próprio profissional. Entretanto, como exemplificado no excerto que se segue, ainda é possível perceber a ambivalência do fato de o envolvimento ser inevitável: "Tu não pode manter isso [envolvimento emocional] como rotina na tua vida, mas também tu não pode fugir disso, porque tu é um ser humano. Tu te envolve, não adianta!" (ENF2).

Essa ambiguidade pode estar relacionada à escamoteação da morte na UTI pediátrica. Compreende-se que o envolvimento emocional é inerente à condição humana e ao trabalho na saúde, porém o fato de alguns profissionais tentarem não se envolver emocionalmente com o paciente pode representar um meio de apaziguar as repercussões da morte e o sofrimento relacionado a ela (Sulzbacher, Reck, Stumm, \& Hildebrandt, 2009), ou seja, o distanciamento é empregado com o intuito de evitar prejuízos emocionais e psicológicos: "Eu acho que a gente tem que ter essa separação, porque senão a gente acaba sofrendo muito" (ENF3).

Com efeito, alguns participantes relataram procurar não se colocar no lugar dos familiares da criança falecida, compreendendo isso como uma postura perigosa, que os colocaria frente à possibilidade a finitude de seus entes queridos. Com isso, percebeu-se a fragilidade de pensar a morte próxima de si, isto é, no seu núcleo familiar: "Eu não consigo me colocar na situação, não quero nunca me ver na situação que eles vivem" (ENF1).

Para Aguiar et al. (2006) o convívio constante com o processo de morrer pode favorecer os profissionais a tornarem-no natural, ou ainda a significarem-no com frieza. No contexto hospitalar, muitas vezes, entende-se que o bom profissional não se envolve com o paciente; portanto, não havendo lugar para a expressão dos sentimentos, o sujeito pode negá-los e ocultá-los (Aguiar et al., 2006). Nesse sentido, a respeito da reação da equipe diante da morte, os enfermeiros e médicos entrevistados relataram que as respostas variam para cada profissional, dependendo essencialmente de suas próprias características e experiências pessoais. Assim, não houve uma resposta unânime do grupo, excetuando-se a concepção de que a equipe como um todo possuía um bom feedback diante do falecimento de pacientes, sendo este entendido como dar continuidade ao trabalho, não permitindo que possíveis ocorridos atrapalhem o dinamismo da unidade: "A gente tem que administrar a unidade, então parece que a gente tem que ser mais forte mesmo, pra mostrar que essa parte a gente trabalha melhor" (ENF3).

Esses achados vão ao encontro do estudo de Gerow et al. (2010), no qual os profissionais, com a intenção de manter ou retornar às atividades profissionais, procuravam não expressar seus sentimentos perante a morte de um paciente. Para os autores, isso se relaciona com a crença do que seria o comportamento adequado para um profissional da saúde no contexto hospitalar. Com isso, na tentativa de se ajustar ao funcionamento do trabalho 
entendido como apropriado, os participantes utilizam recursos defensivos. Entres esses, assim como no estudo de Aguiar et al. (2006), ressaltou-se a estratégia de conservar distância e demonstrar comportamento de frieza ou ainda um aparente equilíbrio. Da mesma maneira, no presente estudo os participantes relataram que a expressão de sentimentos, que aparentemente se oporia à dinâmica do trabalho, é compreendida como inapropriada. A fala abaixo exemplifica que o profissional diante da morte de uma criança não se permitiu abater a ponto de comprometer o funcionamento do trabalho: "Tem que dar continuidade ao serviço... tu não pode nesse momento te desestruturar e não conseguir mais tratar os outros que estão vivos ali" (MED1).

De fato, para os participantes deste estudo o processo de morrer e suas nuances procuraram ser negados e ocultados. Desse modo, como indicado por Silva e Ruiz (2003), os profissionais agem de modo indiferente e impessoal, sobretudo negando a morte, sendo direcionados por uma lógica adaptativa e mercantil. Além disso, percebeu-se a reprovação de profissionais no que diz respeito ao envolvimento de colegas que sofrem de forma mais expressiva diante do falecimento de uma criança, o que é considerado inapropriado. Essa reprovação evidenciou a ameaça contida nessa expressão mais exacerbada de sofrimento, uma vez que revelaria as realidades que procuram ser ocultadas pelo grupo. Desse modo, como afirma Dejours (1992), a participação de todos os interessados sustenta a eficácia dos recursos empregados, isto é, o indivíduo que não partilha do conteúdo ideológico do grupo é excluído como forma de manutenção da defesa. Portanto, para esse autor, nota-se o motivo de um indivíduo isolado de seu grupo social estar violentamente desprovido de defesas perante a realidade que o confronta.

Nesse sentido, diante de um atendimento de urgência/emergência os profissionais expressaram canalizar seu foco totalmente para o aspecto profissional e técnico do atendimento, uma vez que aspectos emocionais foram percebidos como contraproducentes à resposta necessária à demanda prioritária daquele momento. Com isso, percebeu-se a importância do controle dos sentimentos e pensamentos para o desempenho da tarefa de trabalho em equipe, sendo colocados como inviáveis os comportamentos destoantes. Além disso, constatou-se que o medo da morte e do morrer também foi empregado como estímulo para manter a equipe coesa, assim como foi explorado a favor do trabalho. Da mesma maneira, Dejours (1992) afirmou que, algumas vezes, o sofrimento no trabalho pode servir como um instrumento de rendimento profissional, como pode ser exemplificado no trecho a seguir: "Na hora da urgência é a parte profissional que vem primeiro" (MED3).

Nesse ínterim, evidenciou-se a complexidade do lidar com a morte, ressaltando-se a relevância desta ser abordada e pensada pelos profissionais. No entanto, a dificuldade de falar das situações de morte pode ser evidenciada através da alegação de que não se sabe falar da temática ou, ainda, devido a sentimentos provindos de experiências pessoais (Palú et al., 2004). Neste estudo, os participantes expressaram vivenciar a morte dos pacientes comumente em silêncio, sem palavras, legitimando a necessidade de criar possibilidades para o que não é dito, mas é vivenciado: "Acaba todo mundo sofrendo calado" (MED1); "A gente precisa aqui na unidade, a gente até, conversando entre nós, é trabalhar sobre isso [a morte] com a gente mesmo" (ENF3).

Em contrapartida, a morte também pôde ser significada, ainda que raramente, como um evento certo, não como uma prerrogativa ou desgraça específica para um sujeito (Vieira et al., 2006). Assim, as limitações inerentes ao viver e ao desempenho profissional foram inclusive apresentadas como possíveis de serem elaboradas: "A gente tem uma limitação, existe essa limitação, todo tratamento que a gente acaba fazendo em termos de medicina intensiva pediátrica tem uma limitação, ou seja, tem um fim" (MED1); "Tu tem que ter consciência dos teus limites humanos e profissionais. Isso é o mais importante, então se despindo de todo o egocentrismo que possa ter, a coisa anda melhor, não só pro médico, mas como pro pessoal da enfermagem" (MED2). 
Nesse complexo processo do viver-morrer, é de grande valor o fato de que os profissionais que atuam nesse contexto possam trabalhar com o seu mundo interno e com as questões relativas às circunstâncias atemorizantes. Salienta-se a relevância de que os sentimentos sejam trabalhados, vindo à consciência e passando pelo processo de elaboração, facilitando o trabalho com fatores inevitáveis como a morte (Pessini \& Bertachini, 2004). Por elaboração, entende-se aquilo que diz respeito à produção de sentido, havendo um ordenamento de material não simbolizado por meio da palavra. O sujeito pode elaborar dando um destino àquilo que insiste em não ser representado (Freud, 1914/1990). Para Mattos et al. (2009) as pessoas evitam falar, pensar, conviver e, na maioria das vezes, enfrentar o processo de morte e morrer. Porém, conforme o autor, refletir e repensar as reações concernentes a esse processo pode levar a um maior conhecimento acerca de si mesmo, permitindo que os profissionais de saúde repensem a significação da morte e o modo como estão se preparando para lidar com ela em seu cotidiano de trabalho.

Considerando-se o que foi exposto, compreende-se que existem diversos aspectos conflitantes que se impõe aos enfermeiros e médicos que trabalham na UTI pediátrica no tocante à morte. Pode-se considerar uma das limitações desta investigação seu caráter transversal, a partir dos relatos de enfermeiros e médicos de uma UTI pediátrica. Dados longitudinais também podem implementar os resultados de futuras pesquisas, assim como incluir outras categorias profissionais e outros contextos.

No presente estudo, frequentemente, a morte foi significada como fracasso, sendo que os participantes a vivenciaram com sentimentos de incapacidade e impotência. Com isso, a morte exigiu desses enfermeiros e médicos meios de minimizar seus efeitos. Isto é, percebeu-se que ela foi escamoteada e que os participantes buscaram se tornar insensíveis ao sofrimento vinculado à mesma. No entanto, por diversas vezes, na relação profissional-paciente e no trabalho na UTI pediátrica, a morte foi promotora

692 de sofrimento ou ainda se fez perceptível por meio de nuances que revelaram o emprego de recursos lenitivos que tentaram apaziguar ou deslocar suas repercussões.

A respeito disso, Freud (1900/1990) diz que o deslocamento consiste, essencialmente, numa operação de substituição de elementos representacionais conflitantes por outros mais anódinos por meio de um deslizamento associativo. Com efeito, apesar de alguns participantes chegarem a reconhecer a morte como algo inerente ao hospital e à vida, bem como a associá-la a repercussões negativas em seus cotidianos, o fato dessas situações remeterem a suas próprias perdas e, em última análise, a suas próprias mortes, não foi percebido. Esse caráter de desconhecimento, a propósito, é, segundo Freud (1900/1990), efeito do próprio processo de deslocamento.

Nesse ínterim, entende-se que é a partir da formação pessoal e profissional que esses participantes significam a morte no contexto da UTI pediátrica. Desse modo, o mundo interno, assim como a formação acadêmica de cada um, necessitam ser trabalhados no que diz respeito à morte $\mathrm{e}$ ao processo de morrer, com o intuito de promover uma melhor preparação desses profissionais e, de modo semelhante, desenvolver estratégias diante do sofrimento. De fato, de acordo com Yu e Chan (2010), quando a equipe de saúde entende o luto relativo à morte de um paciente, esta consegue prestar apoio a si própria e aos familiares daquele que faleceu. Assim, a fala apresenta-se como um recurso terapêutico. De fato, compartilhar os sentimentos relativos ao processo de finitude e ao luto pode evitar possíveis complicações psíquicas (Aguiar et al., 2006). No entanto, falar acerca disso é algo difícil, e é ainda mais complexo conviver em um ambiente onde isso se faz presente, como é o caso da UTI pediátrica (Mattos et al., 2009). Com efeito, é justamente nessas questões que o profissional de psicologia pode colaborar mais expressivamente, ajudando médicos, enfermeiros e outros profissionais a empregar a palavra enquanto elemento organizador da realidade psíquica. Desse modo, pode-se sugerir a estruturação de propostas educativas que abarquem oficinas de sensibilização, 
programas de educação continuada, bem como espaços de grupos operativos ou terapêuticos, os quais possam abordar a temática da morte e do processo de morrer.

\section{Referências}

Aguiar, I. R., Veloso, T. M. C., Pinheiro, A. K. B., \& Ximenes, L. B. (2006). O envolvimento do enfermeiro no processo de morrer de bebês internados em unidade neonatal. Acta Paulista de Enfermagem, 19(2), 131-137.

Ariès, P. (2003). História social da criança e da família. Rio de Janeiro: Edições Guanabara Koogan.

Azambuja, E. P. D., Pires, D. E. P., Vaz, M. R. C., \& Marziale, M. H. (2010). É possível produzir saúde no trabalho da enfermagem? Texto \& Contexto Enfermagem, 19(4), 658-66.

Bardin, L. (2008). Análise de conteúdo (11 $11^{\mathrm{a}}$ ed.). Lisboa: Edições 70.

Beckstrand, R. L., Rawle, N. L., Callister, L., \& Mandleco, B. L. (2010). Pediatric nurses' perceptions of obstacles and supportive behaviors in end-of-life care. American Journal of Critical Care, 19(6), 543-552.

Borges, K. M. K., Genaro, L. T. G., \& Monteiro, M. C. (2010).Visita de crianças em unidade de terapia intensiva. Revista Brasileira de Terapia Intensiva, 22(3), 300-304.

Brasil. Conselho Nacional de Saúde. (1996). Resolução $n^{\circ} 196$, de 10 de outubro de 1996. Aprova as diretrizes e normas regulamentadoras de pesquisas envolvendo seres humanos. Diário Oficial da União, vol. 134, n 201, out. 1996, Seção 1, p.21082-21085.

Brasil. Conselho Federal de Psicologia. (2000). Resolução CFP n ${ }^{\circ} 016$, de 20 de dezembro de 2000. Dispõe sobre a realização de pesquisa em Psicologia com seres humanos. Diário Oficial da União, n² 246, dez. 2000, Seção 1, p. 91.

Davies, B., Clarke, D., Connaughty, S., Cook, K., MacKenzie, B., McCormick, J., ... Stutzer, C. (1996). Caring for dying children: Nurses' experiences. Pediatric Nursing, 22(6), 500-507.

Denzin, N. K., \& Lincoln, Y. S., (Eds.). (1994). Handbook of qualitative research. Thousand Oaks: Sage Publications.

Dejours, C. (1992). A loucura do trabalho: estudo de psicopatologia do trabalho. São Paulo: Cortez.

Dejours, C. (1994). Psicodinâmica do trabalho: contribuições da Escola Dejouriana à análise da relação prazer, sofrimento e trabalho. São Paulo: Atlas.

Dias, E. O. (2003). A transicionalidade e o mundo cultural. In Dias, E. O. A teoria do amadurecimento de D. W. Winnicott. Rio de Janeiro: Imago.
Freud, S. (1990). La interpretación de los sueños. In J. Strachey (Org.), Obras Completas (Vol.4-5). Buenos Aires: Amorrortu. (Originalmente publicado em 1900).

Freud, S. (1990). Recordar, repetir y reelaborar. In J. Strachey (Org.), Obras completas (Vol.12, pp.151154). Buenos Aires: Amorrortu. (Originalmente publicado em 1914).

Freud, S. (2004). Luto e melancolia. In S. Freud. Escritos sobre a psicologia do inconsciente (Vol.1, pp.99-122). Rio de Janeiro: Imago. (Originalmente publicado em 1917).

Gerow, L., Conejo, P., Alonzo, A., Davis, N., Rodgers, S., \& Domian, E. W. (2010). Creating a curtain of protection: Nurses' experiences of grief following patient death. Journal of Nursing Scholarship, 42(2), 122-129.

Mattos, T. A. D., Lange, C., Cecagno, D., Amestoy, S. C., Thofehrn, M. B., \& Milbrath, V. M. (2009). Profissionais de enfermagem e o processo de morrer e morte em uma unidade de terapia intensiva. Revista Mineira de Enfermagem, 13(3), 337-342.

Minayo, M. C. S. (Org.). (2010). Pesquisa social: teoria, método e criatividade. Petrópolis: Vozes.

Osório, L. C. (2003). Psicologia grupal: uma nova disciplina para o advento de uma era. Porto Alegre: Artmed.

Palú, L. A., Labronici, L. M., \& Albini, L. (2004). A morte no cotidiano dos profissionais de enfermagem de uma unidade de terapia intensiva. Cogitare Enfermagem, 9(1), 33-41.

Pessini, L., \& Bertachini, L. (2004). Humanização e cuidados paliativos. São Paulo: Edições Loyola.

Ribeiro, M. C., Baraldi, S., \& Silva, M. J. P. (1998). A percepção da equipe de enfermagem em situação de morte: ritual do preparo do corpo "pós-morte". Revista da Escola de Enfermagem USP, 32(32), 117-123.

Robson, C. (1993). Real world research: A resource for social sciences and practioner-researcher. Oxford: Blackwell.

Sanches, P. G., \& Carvalho M. D. B. (2009). Vivência dos enfermeiros de unidade de terapia intensiva frente à morte e o morrer. Revista Gaúcha de Enfermagem, 30(2), 289-96.

Silva, A. L. L., \& Ruiz, E. M. (2003). Cuidar, morte e morrer: significações para profissionais de Enfermagem. Estudos de Psicologia (Campinas), 20(1), 15-25. http://dx. doi.org/10.1590/S0103-166X2003000100002

Silva, A. L. P. (2003). O acompanhamento psicológico a familiares de pacientes oncológicos terminais no cotidiano hospitalar. Interação em Psicologia, 7(1), 27-35.

Silva, L. C. S. P., Valença, C. N., \& Germano, R. M. (2010a). Estudo fenomenológico sobre a vivência da morte em 
uma unidade de terapia intensiva neonatal. Revista Brasileira de Enfermagem, 63(5), 770-774.

Silva, L. C. S. P., Valença, C. N., \& Germano, R. M. (2010b). Percepções dos profissionais de enfermagem intensiva frente a morte do recém-nascido. Revista Brasileira de Enfermagem, 63(2), 238-242.

Shorter, M., \& Stayt, L. C. (2010). Critical care nurses' experiences of grief in an adult intensive care unit. Journal of Advanced Nursing, 66(1), 159-167.

Sulzbacher, M., Reck, A. V., Stumm, E. M. F., \& Hildebrandt, L. M. (2009). O enfermeiro em unidade de tratamento intensivo vivenciando e enfrentando situações de morte e morrer. Scientia Medica, 19(1), 11-16.
Turato, E. R. (2003). Tratado da metodologia da pesquisa clínico-qualitativa. Petrópolis: Vozes.

Vieira, M. A., Souza, S. J., \& Sena, R. R. (2006). Significado da morte para os profissionais de enfermagem que atuam no CTI. Revista Mineira de Enfermagem, 10(2), 151-159.

Yu, H. U., \& Chan, S. (2010). Nurses' response to death and dying in an intensive care unit: A qualitative study. Journal of Clinical Nursing, 19(7-8), 1167-1169.

Recebido: maio 10, 2013

Versão final: novembro 21, 2013

Aprovado: dezembro 18, 2013 